\title{
Spatializing the modelled impacts of future climate change - a case study on wheat in the Western Cape
}

\author{
Michael Wallace \\ Western Cape Department of Agriculture, South Africa, mikew @elsenburg.com
}

DOI: http://dx.doi.org/10.4314/sajg.v7i2.6

\begin{abstract}
Analysis and interpretation of future climate change impacts on a particular crop, require a number of different models and datasets. Such datasets often operate at vastly disparate spatial scales. Mechanistic crop models, for example, classically operate at a site-specific, point location, for which soil and climate must be described in great detail. Future climate scenarios however, are obtained from various Global Climate Models (GCMs) at a very coarse resolution - typically gridded to $300 \mathrm{~km}$ or more. In order to be useful at a local level they need to be downscaled to a spatial scale useful for local analysis. Weather monitoring station locations in the province are irregularly distributed - much denser in the fruit and vine areas than in the extensive wheat areas. The Western Cape Province is a highly diverse region with regard to geology, topography, climatic influences and the resulting agricultural systems and practices. Future climate change therefore, is likely to have different impacts in different zones of the province where wheat is produced. To address this heterogeneity, the province was divided into 21 distinct response zones for modelling purposes. Geographic Information Systems (GIS) play a key role in addressing the spatial complexities - facilitating issues such as weighted average zonation, aggregation (or disaggregation) of spatial components, local parameterisation of crop models through interpolation, integration of ancillary data such as satellite imagery within the modelling framework and finally in the spatial analysis and display of modelled scenarios. This paper uses a recent climate impact study in the Western Cape to demonstrate the role of GIS in the assessment of expected climate change impacts on dryland wheat agriculture.
\end{abstract}

\section{Introduction}

A number of studies, both international and local have indicated that South Africa and in particular the Western Cape, is expected to become warmer and probably drier (Niang et al., 2014; WCDoA and WCDEA\&DP, 2016). Considerable work has been done in recent years in assessing the potential impacts of climate change on the local climate through the application of downscaling techniques to Global Climate Models (GCMs). The source GCMs are coarse in resolution, (in the 
region of $300 \times 300 \mathrm{~km}$ ) and need to be downscaled to account for local variables and variations. Local experts are internationally acclaimed in the field of downscaling (Hewitson and Crane, 2006).

A detailed climate change report on the Western Cape was prepared for the provincial government in 2007 (One World Sustainable Investments, 2007). The report indicated a strong likelihood of warming, reduced rainfall in the western parts of the province, with increased frequency and intensity of extreme events towards mid- $21^{\text {st }}$ century, based on modelling undertaken by Hewitson and colleagues at the Climate Systems Analysis Group (CSAG) at the University of Cape Town. Further investigation culminated in a detailed analysis response framework, highlighting the vulnerability of the agricultural sector in this region and setting forth a strategic action plan (WCDoA and WCDEA\&DP, 2016).

The Western Cape however, is a highly diverse region with regard to topography, soil types and climate. This variability dictates the need for either subtle or distinct differences in farming systems and practices in different sub-regions. This is evident upon examination of the wide range of agricultural activities in the 80 relatively homogeneous farming areas (RHFAs) in the Western Cape (One World Sustainable Investments, 2007). For this reason, in order to properly assess the potential impacts of climate change on agriculture in the Western Cape, it is unrealistic to provide "blanket" climate impact estimations for the province as a whole. A spatial or geographic approach is required, in combination with appropriately downscaled climate data and crop production models, in order to assess the sensitivity or vulnerability of various commodities to climate change based on their location. Wheat (Triticum aestivum) is the most important field crop in the Western Cape (Ziervogel and Taylor, 2008) and the most extensively grown commodity in the province and was thus the focus of the study upon which this review is based.

A variety of crop models exist and have particular strengths and weaknesses, particularly in the context of spatial applications (Nagamani et al., 2017). Such models are increasingly used to test the impacts of expected climate change at a detailed physiological level. Parameterization and operation of mechanistic crop models is a highly intricate and specialised endeavour, as is the process of deriving downscaled future scenarios from GCMs. Whilst the technicalities of these are beyond the scope of this review, the following section provides some background on these processes with special reference to the spatial imperative in their local application. Section 3 demonstrates an example of using geospatial analysis in reconciling the various spatial zones to an acceptable compromise given the unavoidable spatial disparity in the input data.

\section{Crop model parameterization}

Process-based crop models are essentially collections of mathematical equations that represent the various processes occurring within the plant and the interactions between the plant and its environment. Owing to the complexity of biological and environmental systems it is impossible to 
fully represent the system in mathematical terms; thus such models condense current knowledge and assumptions regarding these processes and interactions to seek a simplified representation of reality. A number of crop models could be considered, ranging from simple (experience and ratebased climatic threshold yield functions) to the complex (which consider genetics, physiology, phenology \& management based growth, development and yield functions) (after Schulze, 2007). For this exercise, a complex model was used, known as APSIM (Agricultural Production Systems Simulator). Models at this level are primarily designed for use by researchers and require a considerable level of agronomic training and experience. However, the development and level of maturity of the APSIM model (Keating et al., 2003) with its rigorous and disciplined validation (Holzworth et al., 2014), ongoing, vigorous development (Brown et al., 2018) and extensive testing in environmental conditions similar to those experienced in the Western Cape, in particular in the Mediterranean climate zones of Western Australia (Ludwig and Asseng, 2006) made this an attractive option for modelling local winter wheat production. In other developed countries, considerable support is available to the crop modeller in terms of predefined soil and crop files. In South Africa however, these need to be defined by the user which can present a considerable hurdle. Although these crop simulation models are designed to be site-specific, the incorporation of GIS provides a number of advantages both in terms of model input, spatial and temporal analysis and in the visualization of modelled results (Hodson and White, 2010).

\subsection{Soil inputs}

In order to run the APSIM model, a number of exacting criteria need to be met in terms of the input files. The most onerous of these is the requirement for highly detailed, multi-layer soil descriptions. The most fundamentally important characteristic of soils in a water-limited growing environment such as the Western Cape is the calculated Plant Available Water Capacity (PAWC) of the representative soil to be used per zone (Burk and Dalgliesh, 2008). This is calculated based on a number of soil physical properties (beyond the scope of this review). The primary source of many of these input data was the National Land Type Inventory (ARC-ISCW Land Type Survey Staff, 1972) provided as so-called "modal profiles" (detailed soil physical and chemical descriptions at a point location) and the well-known GIS Land Type data with its accompanying memoirs. Also of great help in terms of the hydrological and pedotransfer properties required, was the source soils data for the ACRU hydrological model (Schulze et al., 1995) - known as AUTOSOILS - provided as attributed GIS polygons corresponding to the Land Types. The natural spatial unit then, for this component of the model inputs, was the Land Type polygon dataset. From the various input datasets, some 18 different APSIM soil parameters per layer, per location could be derived and defined per Land Type polygon. 


\subsection{Climate inputs}

The study used two different approaches to examine the impacts of climate change:

i. Using an observed, historic climatology of daily data that is changed - or "perturbed" by specified amounts or percentages to reflect those changes predicted in academic literature for a specified future time period. In other words, to simulate the resulting yield from an estimated increase of say, $10 \%$ in rainfall, the historic record is increased by $10 \%$ (at each daily time-step). Combinations of temperature, rainfall, solar radiation and atmospheric $\mathrm{CO}_{2}$ levels can thus be examined (Tarul et al., 2018). This approach is sometimes termed a "sensitivity analysis".

ii. Using ensembles of future scenarios generated by downscaled GCM projections with stochastically generated daily records. In each case, the model is run on (or "forced by") the baseline climate and again on the future scenario and the resulting anomalies are calculated to examine the impacts of the changed climate.

Each of the methods has advantages and disadvantages. Whilst the first may not account for future changes in spatial and temporal pattern changes, the latter is beset with unavoidable uncertainties due to the complexity and randomness in the nature of climate. Even the downscaling process cannot remove the inherent uncertainty in the "parent" GCM (Wilby et al., 2004; Tarul et al., 2018).

The spatial unit for this component of the study was the so called "Quinary" catchment database, initially designed for hydrology modelling (Schulze and Horan, 2010). Courtesy of this project, a set of 20 years of cleaned, patched, uninterrupted, observed daily climate data for the entire country was made available and utilised in this study as the observed "baseline". To provide plausible future climate scenarios, the downscaling of a set of eight GCMs from various scientific centres around the world (as endorsed by the Intergovernmental Panel on Climate Change - IPCC) was undertaken at weather station (point) scale using methodologies described by Hewitson and Crane (1996) and Hewitson (2007). Thus for each final study zone, downscaled GCM data for a representative station nearest to or within the zone would be selected and allocated using simple spatial analysis.

\subsection{Other inputs}

A number of other inputs are required by the crop model. In terms of management practices a range of parameters must be set. These include fertilization (initial and post-planting), row spacing, plant density, planting date and cultivar choice (which requires prior definition of some cultivar characteristics). Many of these practices vary according to the inherent potential and local geography of the wheat zone. This introduces a third spatial unit - that which defines the inherent wheat production and corresponding farming systems and management practices per zone. A 
number of agro-ecological zones, known as the relatively homogeneous farming areas (RHFAs) were identified by scientists and extension workers during the 1970s, where farming practices, soils and climate were relatively similar. With the advent of GIS and remote sensing, these zones have been refined (by the author) and modified during the last decade. Some 80 of these zones are currently demarcated for the province. These zones can be examined on the CapeFarmMapper, a spatial Web portal, at https://gis.elsenburg.com/apps/cfm/ (WCDoA, 2018). Wheat production can be considered the primary agricultural enterprise in 10 of these zones, whilst playing a significant role in a further 11 zones in the small-stock/small grain milieu (Department of Agriculture Western Cape, 1990). The 21 zones shown in Figure 1 were ultimately selected as the most appropriate spatial zones for modelling crop yields and display of the results.

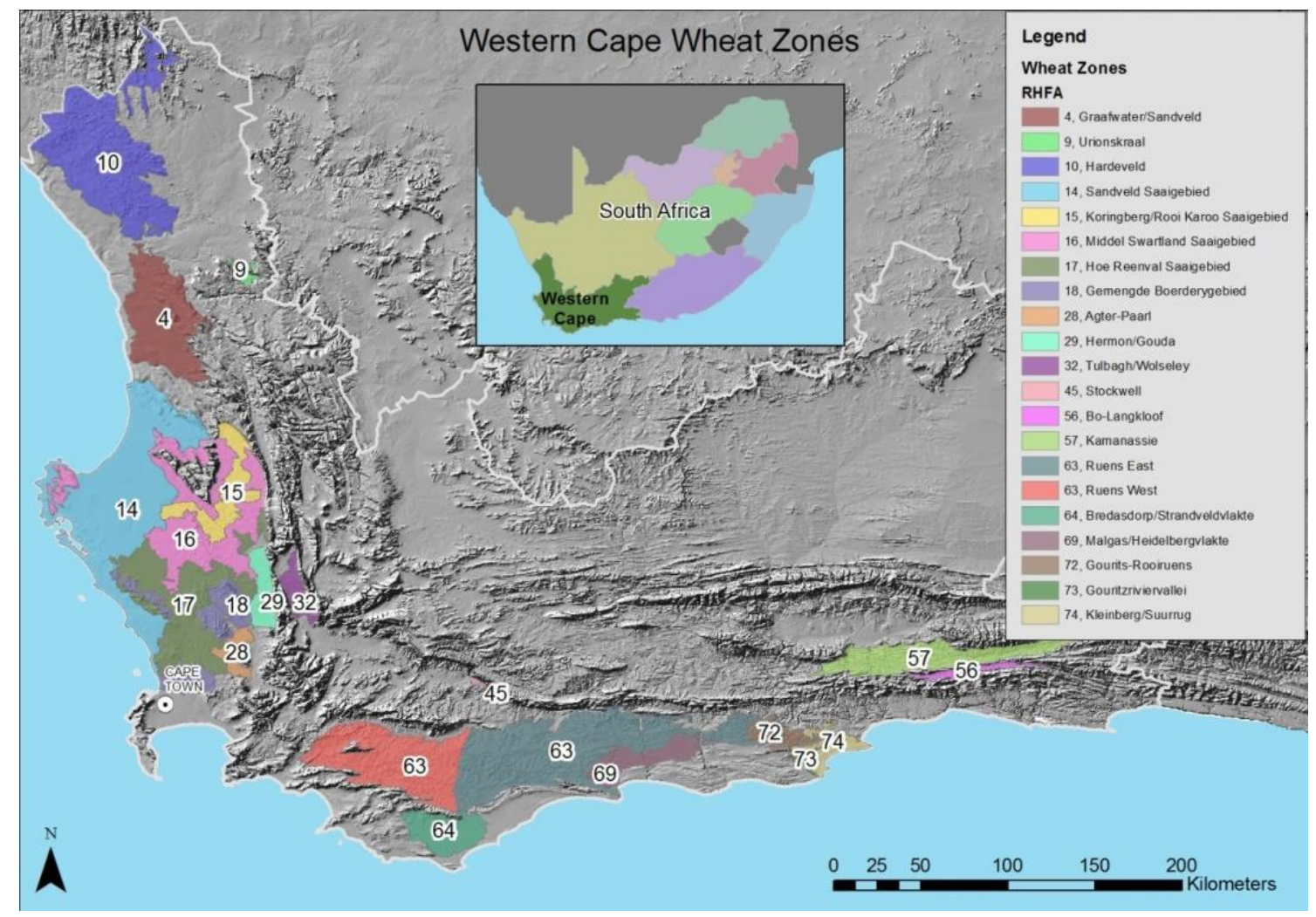

Figure 1. Wheat production zones in the Western Cape Province of South Africa as used in this study

A final and surprisingly interesting parameter is set before running the model - the atmospheric $\mathrm{CO}_{2}$ level. Increased $\mathrm{CO}_{2}$ levels contribute significantly to increased wheat yield (O'Leary et al., 2015; Ainsworth and McGrath, 2010). (This $\mathrm{CO}_{2}$ "fertilization" effect was subsequently found to vary spatially across the province in response to temperature and moisture regimes as dictated by rainfall and soil spatial variation).

Whilst not a model input per se, a further spatial unit, fundamental to the study, was the detailed crop map resulting from an aerial mapping and observation exercise known at the "Flyover" (Wallace, 2013b). This exercise, first undertaken in 2013, maps every cultivated field with its 
corresponding commodity at that time. This polygon dataset was key to accurately identifying wheat areas for stratification of remote sensing data (Section 4) and to derive weighted averages from underlying soil parameter zones (Section 3).

\section{Study zone parameterization}

In order to assign meaningful input parameters on a zonal basis to a model that is designed to be run at point scale, a well-considered and scientifically representative methodology needs to be followed. GIS-based weighted averaging, based on best available data, facilitates the assignment of parameter values with some degree of spatial intelligence. The following example illustrates the point.

As described in section 2.1 above, soils are presented as AUTOSOILS polygons, based on the Land Type boundaries. Since the RHFAs follow Land Type boundaries, the AUTOSOILS features are essentially subset polygons of the wheat RHFAs from section 2.3. Since we accurately know the location of wheat within each AUTOSOILS zone we can use a relatively simple GIS overlay and weighted average technique (to mitigate against "over-averaging"). Figure 2 should demonstrate this point.

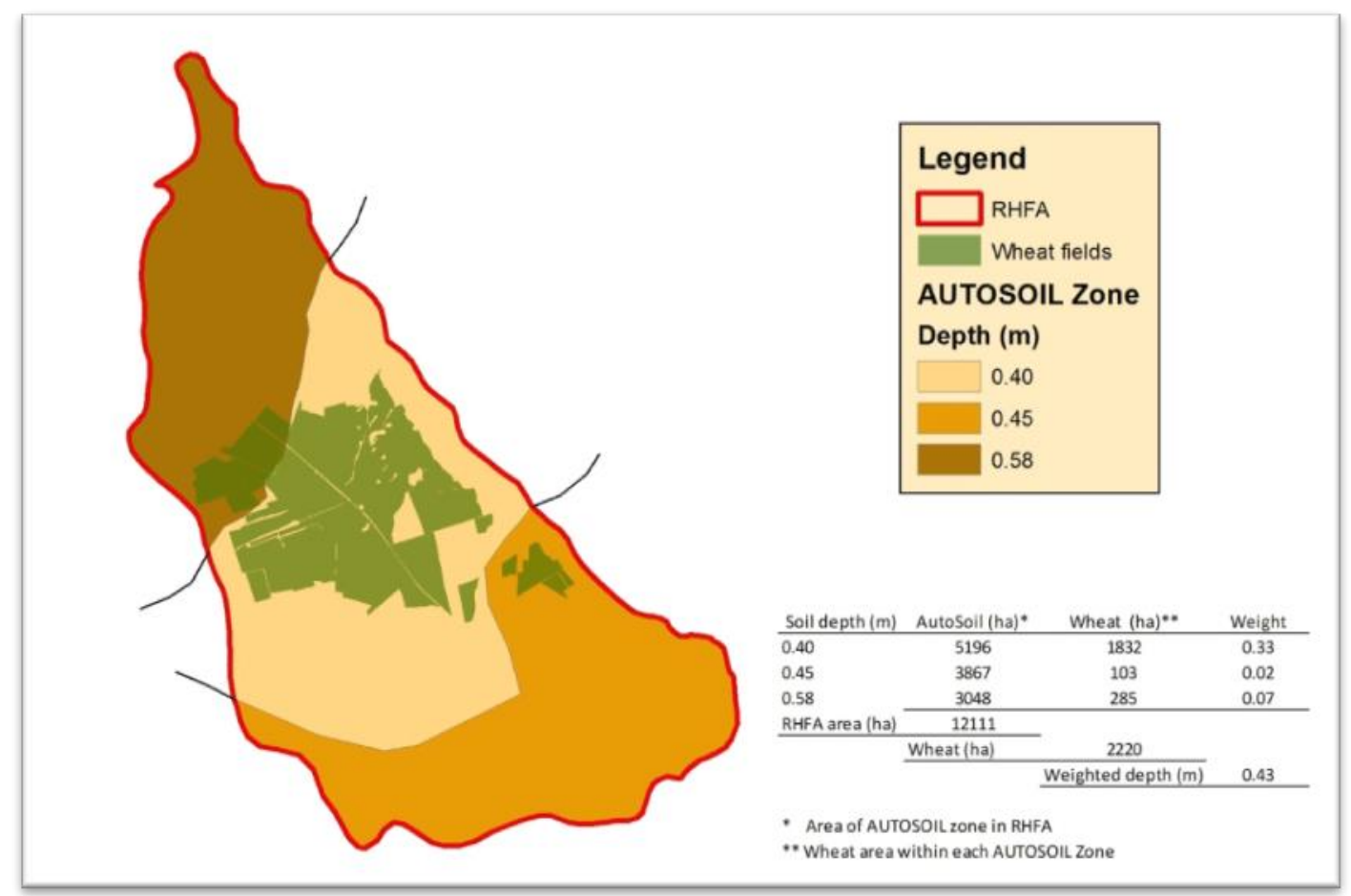

Figure 2. Illustration showing an example of the methodology used to assign area-weighted soil water-holding capacity values (e.g. depth shown in this example) for each RHFA according to the proportion of mapped wheat fields (from the Flyover) from each intersected AUTOSOIL zone per RHFA (Wallace, 2013a). 
The process followed in Figure 2 is simply continued in batch mode to assign the relevant weighting of each parameter to the wheat RHFA to facilitate the calculation of the multiple soil layer parameters required for the APSIM model.

Once some 18 soil and pedotransfer parameters have been defined per soil layer, per zone, the many management and cultivar inputs have been decided upon and the nearest climatology allocated and appropriately formatted, the APSIM crop model is ready to be run. The model output is in the form of large ASCII files containing numerous user-defined outputs. It is only when we put the data into a spatial context that we can clearly conceive or visualize the implications of climate change on wheat yields across the study region. However - one more highly spatiallyrelevant step is required to both validate and facilitate calibration of the model, as discussed in the following chapter.

\section{Model Calibration}

For various reasons there are very few objective, spatially-defined yield data available to verify model runs. Furthermore, there are no actual wheat yield records corresponding to the spatial unit of a RHFA. Thus a novel spatial approach was followed to determine appropriate yield norms for each zone. The use of remote sensing data was explored as a proxy for yield data indicating spatial variation of long-term average wheat yields in the Western Cape. The high correlation between satellite-derived peak NDVI (Normalised Difference Vegetation Index) and final wheat yield (with reported $r^{2}$ values ranging from 0.73 to 0.95 ) have been well utilised by a number of researchers involved in spatial modelling of wheat yield, over a number of years (Becker-Reshef et al., 2010; Moriondo et al., 2007; Aase and Siddoway, 1981; Potgieter, 2009). Recent improvements in sensor technology and data availability, such as the high-quality daily vegetation products from NASA's MODIS data, have made this an attractive option for observing wheat yield variation in the Western Cape.

Although relatively coarse, the $250 \mathrm{~m}$ resolution MODIS data have been shown to be highly suited to wheat yield estimation, particularly where an accurately mapped crop "mask" is available (Becker-Reshef et al., 2010; Potgieter, 2009) as is the case in the Western Cape (with the Flyover data). Two MODIS vegetation index products are available - the more traditional MODIS NDVI and the closely related MODIS EVI (Enhanced Vegetation Index) product which is considered to perform slightly better for wheat analysis (Potgieter, 2009).

Since the correlation between final grain yield and the chosen vegetation index is highest at peak EVI, usually at wheat anthesis (flowering), a preliminary analysis was undertaken to determine the timing of this phenomenon in the Western Cape, which resulted in the mid-August 12-year timeseries of imagery being averaged at the peak EVI. The zonal statistics function of ArcGIS Spatial Analyst was used to analyse the "masked" wheat fields only, across each wheat RHFA. Over a 
time-series of 12 years this gave an indication of wheat production variation across the Western Cape. The average of the 12-year averaged EVI time-series data showed good correlation $\left(\mathrm{r}^{2}>0.8\right)$ with the APSIM modelled yields and aligned well with the advisory "target norm" (after Department of Agriculture Western Cape, 1990) values across the 21 RHFAs. In the absence of sufficient observed yield data, and in light of the high correlation between the vegetation index measure of biomass and the literature supporting good correlation with yield at peak NDVI/EVI, the method provided reassurance that spatial variation across the province was being sensibly modelled. The average of the MODIS EVI time series data is shown in Figure 3 and subsequently serves as a much used "winter dryland wheat production potential" map.

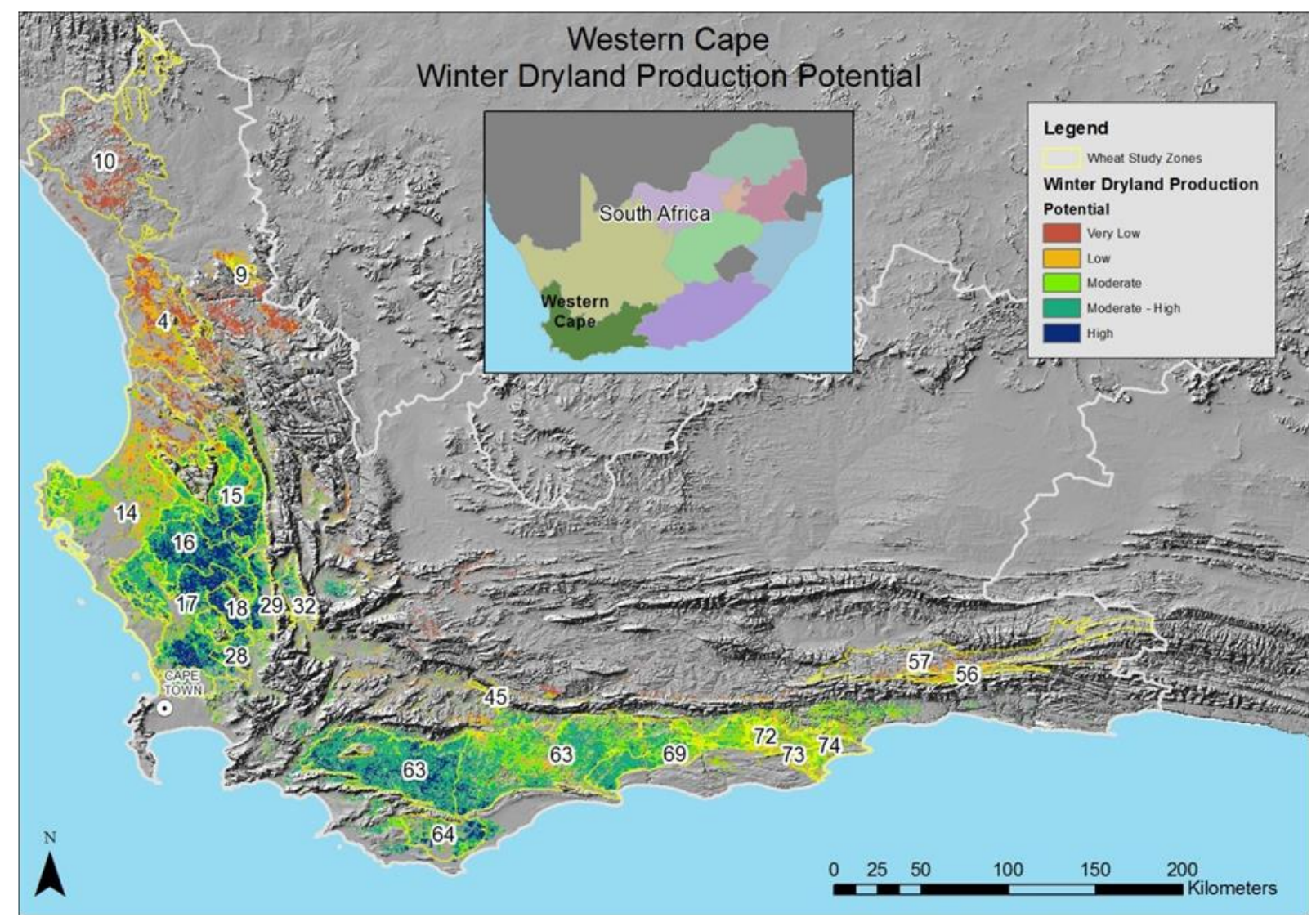

Figure 3. Time series MODIS EVI data at mid-August used in the model calibration (shown here as mapped data available at WCDoA, 2018).

\section{Model results and discussion}

The intention of this paper was to discuss spatial aspects of the entire analysis without dwelling on the rather arcane workflows and statistical analyses involved in modelling climate change. Those requiring more information regarding this modelling process can consult (Wallace, 2013a) and (Schulze et al., 2016) and the references given previously on GCM downscaling. This leaves 
us then with one of the most rewarding aspects of working in the ambit of a spatial framework - the ability to easily display the modelled results as maps.

The following mapped results illustrate some of the final outcomes of the climate change modelling exercise.

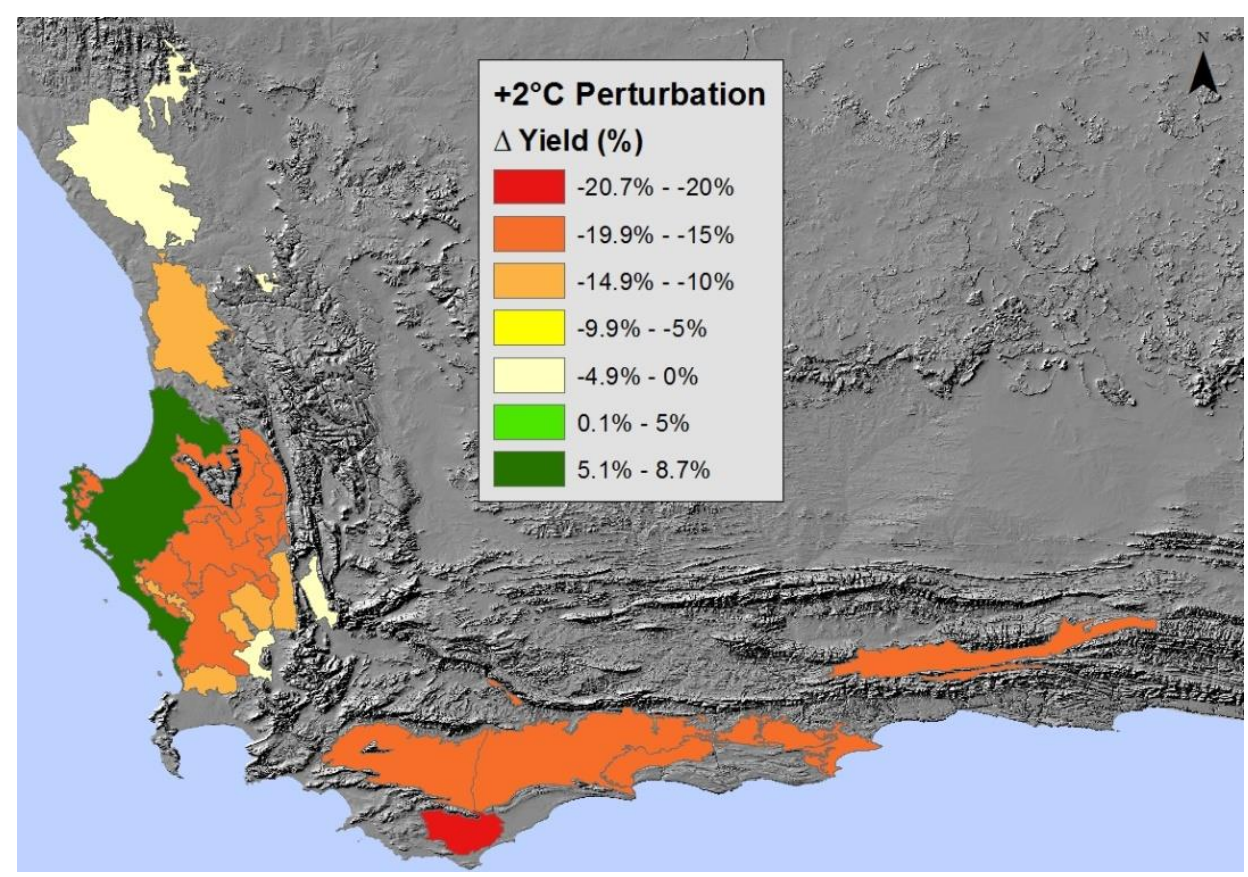

Figure 4. A simple representation of the simulated spatial impact of a $2^{\circ} \mathrm{C}$ temperature increase on wheat yield.

Whilst Figure 4 provides a simple, single factor perturbation, the model allows perturbation of multiple climate factors acting in concert, which can have some non-linear and non-intuitive results (Figure 5). 


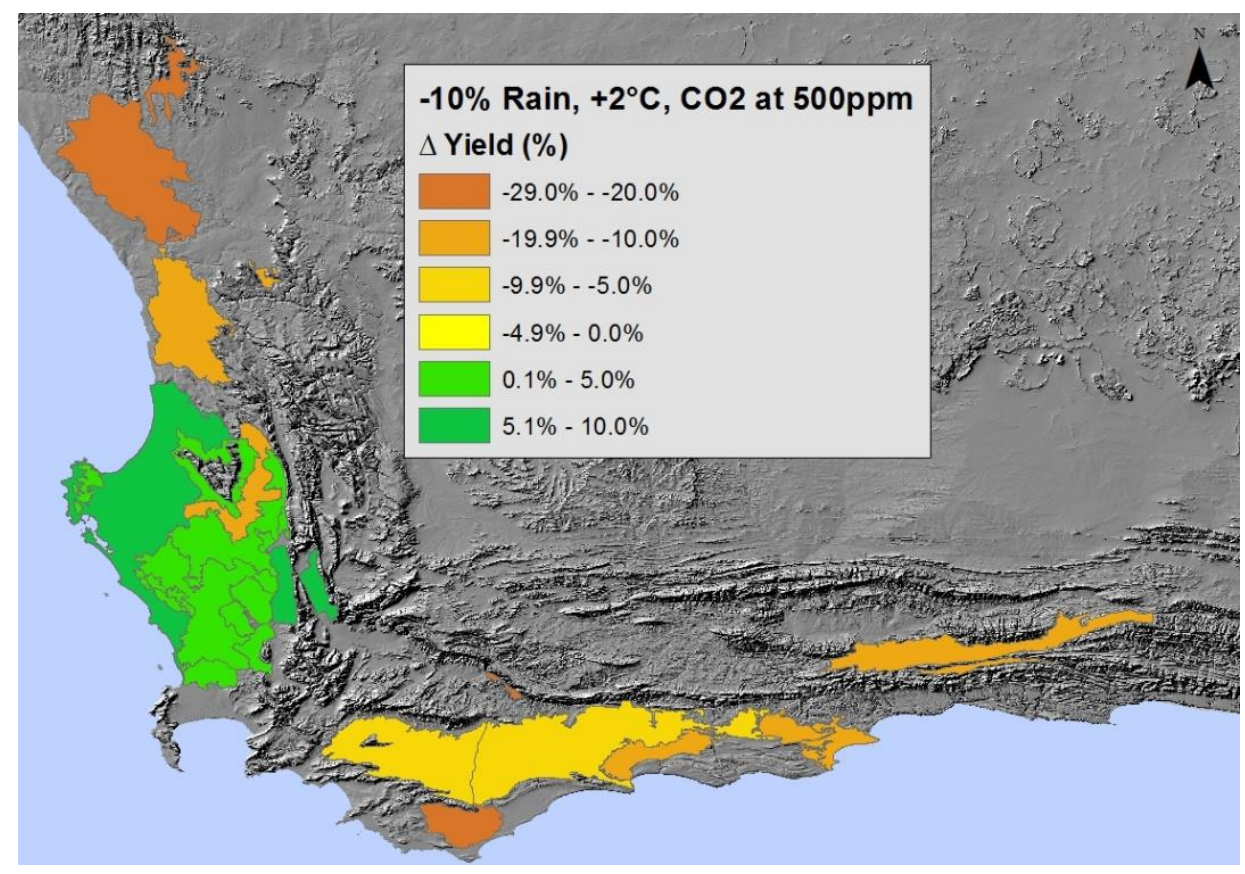

Figure 5. In this example, despite the $2^{\circ} \mathrm{C}$ temperature increase, the yields in the western (Swartland and coastal) regions are improved.

This positive response in the western part of the province in Figure 5 is due largely to the combination of the effects of a simulated increase in atmospheric $\mathrm{CO}_{2}$ and the fact that soils in this region are either deeper (coastal sands) or higher in clay content, resulting in a higher PAWC. Exposure to the cooler Atlantic Ocean also plays a role in moderating temperature increases for the coastal areas.

Figure 6 represents the results of a far more complex workflow, where the model is forced by an ensemble of 8 downscaled climatologies representing the mid-century future. The median outcome of all the model runs within the ensemble "envelope" is presented. This scenario considers the change in spatial and temporal patterns evident in future (GCM-based) climate models, unlike the previous "sensitivity analysis" scenarios which are based on perturbations of historic climate, where patterns are unaltered. The downscaled GCM model projections expect wetter conditions to become more likely to the east of the province and drying likely in the west. The yield scenarios thus appear to contradict the preceding perturbation-based methodology, yet appropriately reflect the expected future change in circulation and rainfall patterns over the province. 


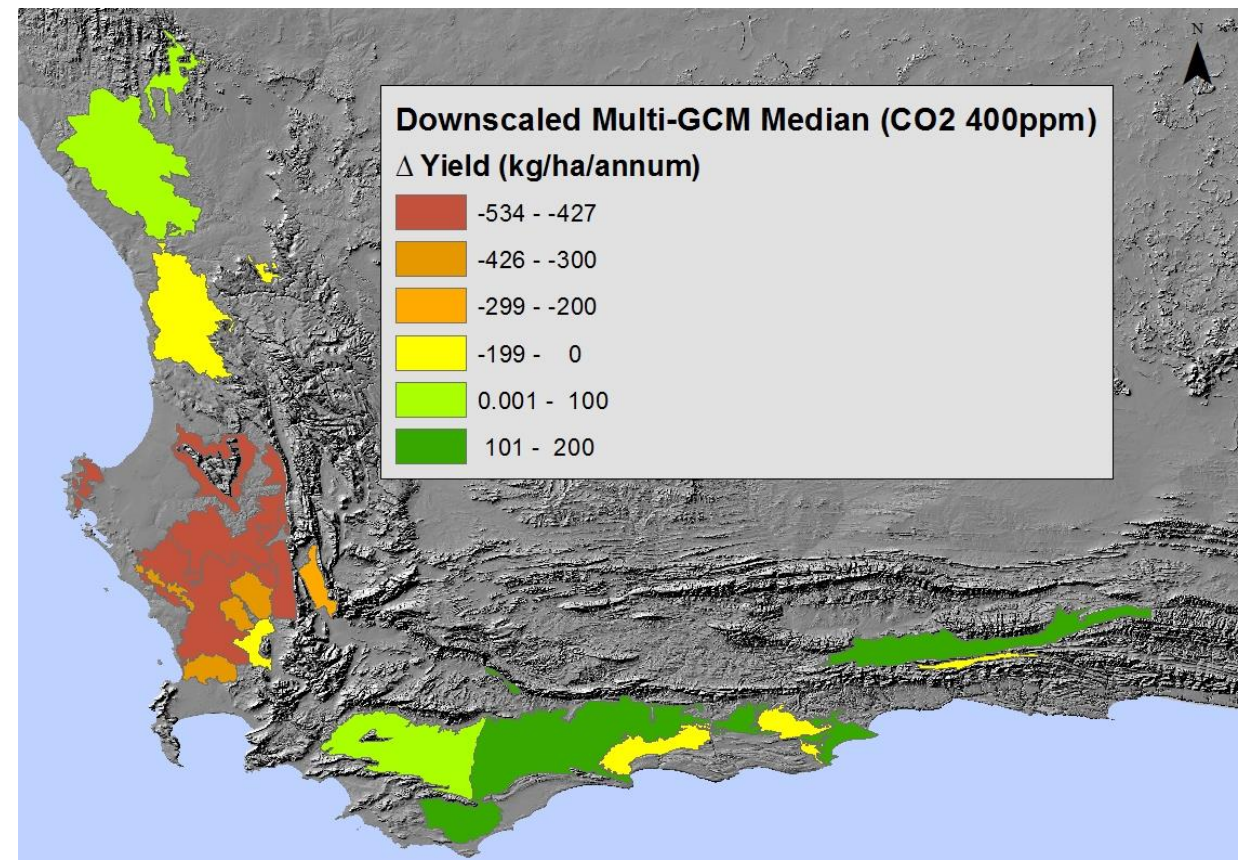

Figure 6. An example of modelled median future (2046-2065) downscaled GCM-forced yield anomalies, modelled at $\mathrm{CO}_{2}$ concentrations of $400 \mathrm{ppm}$. (Increasing the $\mathrm{CO}_{2}$ levels to a potentially plausible level for the future period (500 ppm) improved simulated yields considerably).

\section{Conclusion}

GIS and crop simulation models are two powerful and highly complementary tools that are increasingly used for such predictive analyses. The inherently spatial aspects of climate and climate change make them readily amenable for incorporation into a GIS-based analysis system (Hodson and White, 2010). It is becoming ever more apparent that climatic changes are occurring nonuniformly across regions or agroecosystems - of particular importance in the highly heterogeneous conditions of the Western Cape. The comparisons between the two different approaches to modelling future climate change emphasise their complexity and inherent uncertainties.

Whilst driving the crop model with perturbed historic data provides interesting and useful insight into crop responses under changed climate parameters, it fails to account for the spatial patterns of expected climate change found when the model is driven by the GCM-based climate projections. GIS provides the means to capture this spatial heterogeneity and facilitates the visualization, understanding and communication of the actual or expected changes.

\section{References}

Aase, J. K. \& Siddoway, F. H. 1981. Assessing winter wheat dry matter production via spectral reflectance measurements. Remote Sensing of Environment, 11, 267-277.

Ainsworth, E. A. \& McGrath, J. M. 2010. Direct Effects of Rising Atmospheric Carbon Dioxide and Ozone on Crop Yields, Climate Change and Food Security. In: Lobell, D. \& Burke, M. (eds.) Direct Effects of 
Rising Atmospheric Carbon Dioxide and Ozone on Crop Yields, Climate Change and Food Security. Springer Netherlands.

ARC-ISCW Land Type Survey Staff 1972. Land Types of South Africa: Digital Map (1:250 000 scale) and Memoirs. Pretoria: Institute for Soil, Climate and Water of the Agricultural research Council.

Becker-Reshef, I., Vermote, E., Lindeman, M. \& Justice, C. 2010. A generalized regression-based model for forecasting winter wheat yields in Kansas and Ukraine using MODIS data. Remote Sensing of Environment, 114, 1312-1323.

Brown, H., Huth, N. \& Holzworth, D. 2018. Crop model improvement in APSIM: Using wheat as a case study. European Journal of Agronomy.

Burk, L. \& Dalgliesh, N. 2008. Estimating plant available water capacity - a methodology. Canberra: CSIRO Sustainable Ecosystems.

Department of Agriculture Western Cape 1990. Streeksontwikkelingsplanne (SOP)/Regional Development Plan (RDP). Elsenburg Landbou Ontwikkeling Sentrum.

Hewitson, B. 2007. Developments in downscaling climate change scenarios. Meeting Report: Participant Papers. Nadi, Fiji: IPCC-TGICA.

Hewitson, B. \& Crane, R. 1996. Climate downscaling: techniques and application. Climate Research, 07, 8595.

Hewitson, B. C. \& Crane, R. G. 2006. Consensus between GCM climate change projections with empirical downscaling: precipitation downscaling over South Africa. International Journal of Climatology, 26, 1315-1337.

Hodson, D. \& White, J. W. 2010. GIS and Crop Simulation Modelling Applications in Climate Change Research. In: Reynolds, M. (ed.) Climate Change and Crop Production Mexico: CABI.

Holzworth, D. P., Huth, N. I., deVoil, P. G., Zurcher, E. J., Herrmann, N. I., McLean, G., Chenu, K., Oosterom, E. J. v., Snow, V., Murphy, C., Moore, A. D., Brown, H., Whish, J. P. M., Verrall, S., Fainges, J., Bell, L. W., Peake, A. S., Poulton, P. L., Hochman, Z., Thorburn, P. J., Gaydon, D. S., Dalgliesh, N. P., Rodriguez, D., Cox, H., Chapman, S., Doherty, A., Teixeira, E., Sharp, J., Cichota, R., Vogeler, I., Li, F. Y., Wang, E., Hammer, G. L., Robertson, M. J., Dimes, J. P., Whitbread, A. M., Hunt, J., Rees, H. v., McClelland, T., Carberry, P. S., Hargreaves, J. N. G., MacLeod, N., McDonald, C., Harsdorf, J., Wedgwood, S. \& Keating, B. A. 2014. APSIM - Evolution towards a new generation of agricultural systems simulation. Environ. Model. Softw., 62, 327-350.

Keating, B. A., Carberry, P. S., Hammer, G. L., Probert, M. E., Robertson, M. J., Holzworth, D., Huth, N. I., Hargreaves, J. N. G., Meinke, H., Hochman, Z., McLean, G., Verburg, K., Snow, V., Dimes, J. P., Silburn, M., Wang, E., Brown, S., Bristow, K. L., Asseng, S., Chapman, S., McCown, R. L., Freebairn, D. M. \& Smith, C. J. 2003. An overview of APSIM, a model designed for farming systems simulation. Modelling Cropping Systems: Science, Software and Applications, 18, 267-288.

Ludwig, F. \& Asseng, S. 2006. Climate change impacts on wheat production in a Mediterranean environment in Western Australia. Agricultural Systems, 90, 159-179.

Moriondo, M., Maselli, F. \& Bindi, M. 2007. A simple model of regional wheat yield based on NDVI data. European Journal of Agronomy, 26, 266-274.

Nagamani, K., Mariappan, N. \& Ethirajan, V. 2017. Remote Sensing, GIS and Crop Simulation Models - A Review. Int.J.Curr.Res.Biosci.Plantbiol. 4(8): doi: https://doi.org/10.20546/ijcrbp.2017.408.011, 4, 8092.

Niang, I., Ruppel, O. C., Abdrabo, M. A., Essel, A., Lennard, C., Padgham, J. \& Urquhart, P. 2014. Africa. In: Barros, V. R., Field, C. B., Dokken, D. J., Mastrandrea, M. D., Mach, K. J., Bilir, T. E., Chatterjee, M., Ebi, K. L., Estrada, Y. O., Genova, R. C., Girma, B., Kissel, E. S., Levy, A. N., MacCracken, S., Mastrandrea, P. R. \& White, L. L. (eds.) Climate Change 2014: Impacts, Adaptation, and Vulnerability. 
Part B: Regional Aspects. Contribution of Working Group II to the Fifth Assessment Report of the Intergovernmental Panel of Climate Change. Cambridge, United Kingdom and New York, NY, USA: Cambridge University Press.

O'Leary, G. J., Christy, B., Nuttall, J., Huth, N. \& Cammarano, D., Stöckle, C. , Basso, B. , Shcherbak, I. , Fitzgerald, G., Luo, Q., Farre-Codina, I. , Palta, J. and Asseng, S. 2015. Response of wheat growth, grain yield and water use to elevated $\mathrm{CO} 2$ under a Free-Air CO2 Enrichment (FACE) experiment and modelling in a semi-arid environment. Global Change Biology, 21, 2670-2686.

One World Sustainable Investments 2007. A climate change response strategy and action plan for the Western Cape. In: Petrie, B. (ed.). Cape Town: Department of Environment Affairs and Development Planning.

Potgieter, A. B. 2009. PhD Thesis: Determining broadacre crop are estimates through the use of multitemporal MODIS satellite imagery for major Australian winter crops. $\mathrm{PhD}$, University of Southern Queensland.

Schulze, R., Angus, G. \& Guy, R. 1995. Chapter 5: Soils. In: Schulze, R. (ed.) A Text to Accompany the ACRU 3.00 Agrohydrological Modelling System. Pretoria: Water research Commision.

Schulze, R. E. 2007. Climate change and the agricultural sector in South Africa: An assessment of findings in the new millenium. In: Schulze, R. (ed.) ACRUcons Report 55. Pietermaritzburg: School of Bioresources Engineering and Environmental Hydrology, University of KwaZulu-Natal.

Schulze, R. E. \& Horan, M. J. C. 2010. Methods I: Delineation of South Africa, Lesotho and Swaziland into Quinary Carchments. Methodological approaches to assessing eco-hydrological responses to climate change in South Africa. In: R.E. Schulze, B.S. Hewitson, K.R. Barichievy, M.A. Tadross, R.P. Kunz, Horan, M. J. C. \& Lumsden, T. G. (eds.) WRC Report 1562/1/10. Pretoria: Water resources Commission.

Schulze, R. E., Schutte, S. \& Wallace, M. 2016. Wheat Production in South Africa and Climate Change. In Schulze, R.E. (ed.) Handbook for Farmers, Officials and Other Stakeholders on Adaptation to Climate Change in the Agricultural Sector within South Africa. Section C: Crops in South Africa and Climate Change $\mathrm{C} 2$.

Tarul, S., H., V., Surbhi, C., Kaustubh, S., Subimal, G. \& Subhankar, K. 2018. Understanding the cascade of GCM and downscaling uncertainties in hydro- climatic projections over India. International Journal of Climatology, 38, e178-e190.

Wallace, M. 2013a. Modelling the Impact of Future Climate Change on Subregional Wheat Production in the Western Cape. Thesis presented for the degree of Doctor of Philosophy in the Department of Environmental and Geographical Science, University of Cape Town. June 2013.

Wallace, M. 2013b. Spatial intelligence - mapping of Agricultural commodities and infrastructure in the Western Cape : taking our services out there. Agriprobe, 10, 12-13.

WCDoA 2018. Western Cape Department of Agriculture: CapeFarmMapper $<$ https://gis.elsenburg.com/apps/cfm/>, viewed 7 May 2018.

WCDoA \& WCDEA\&DP 2016. Western Cape Climate Change Response Framework and Implementation Plan for the Agricultural Sector. Prepared by Midgley, S., Methner, N., New, M., Cartwright, A., Cullis, J., Johnston, P., Knowles, T., Midgley, G., Cole, M., Taylor Parkins, F.

Wilby, R. L., Charles, S. P., Zorita, E., Timbal, B., Whetton, P. \& Mearns, L. O. 2004. Guidelines for Use of Climate Scenarios Developed from Downscaling Methods. IPCC Report.

Ziervogel, G. \& Taylor, A. 2008. Feeling stressed: integrating climate adaptation with other priorities in South Africa. Environment, 50, 32-41. 